\title{
Evaluation of the Effects of Abdominal Liposuction in Improving Metabolic Parameters in Recently Diagnosed Non Complicated Type 2 Diabetes
}

\author{
AWAD H. ELKAYAL, M.D.; BARAKAT ABDELREHEEM MAHMOUD, M.D. and \\ AHMED M.A. ANANY, M.Sc.
}

The Department of General Surgery, Faculty of Medicine, Ain Shams University

\begin{abstract}
Background: Diabetes Mellitus (DM) is a metabolic disorder characterized by the presence of chronic hyperglycemia accompanied by greater or lesser impairment in the metabolism of carbohydrates, lipids and proteins. DM is probably one of the oldest diseases known to man. It was first reported in Egyptian manuscript about 3000 years ago. In 1936, the distinction between type 1 and type 2 DM was clearly made. Type $2 \mathrm{DM}$ was first described as a component of metabolic syndrome in 1988. The origin and etiology of DM can vary greatly but always include defects in either insulin secretion or response or in both at some point in the course of disease.

Obesity is associated with an increased risk of premature death and significantly increases the risk of developing type 2 diabetes mellitus, hypertension, coronary heart disease. Dyslipidaemia is a silent pandemic affecting millions of people around the world. There is controversy of the possible benefit of liposuction or abdominoplasty in the metabolism of glucose or cholesterol. Liposuction was the second most frequently performed aesthetic operation in 2013. As with any surgery liposuction carries risks, however, in recent years, improved techniques have made liposuction safer, easier, and less painful. Thus, any intervention that immediately decreases adiposity and is relatively safe could be a viable method not only for aesthetic purpose but also for increasing the efficiency of insulin and improving metabolic profile, especially when combined with regular exercise and proper diet.
\end{abstract}

Aim of Study: The aim of this study is to evaluate the effectiveness of abdominal liposuction in improving quality of life in newly diagnosed uncomplicated type 2 diabetic patients.

Patients and Methods: This study will take place in plastic Surgery Department, Port Said general Hospital. As total number of cases satisfying inclusion criteria not exceed 6 cases the study period (During 2019-2020) the total sample $3 \times 6=18$ cases all will be included as comprehensive sample.

Results: In our study, the mean FBG was $163 \pm 22 \mathrm{mg} / \mathrm{d} 1$ preoperatively. At three months after surgery, it was

Correspondence to: Dr. Ahmed M.A. Anany, E-Mail: dr.ahmedanany66@gmail.com
$162 \pm 29 \mathrm{mg} / \mathrm{dl}$, but at six months after surgery, it was $147 \pm$ $28 \mathrm{mg} / \mathrm{d} 1$. The mean PPBG was $218 \pm 40 \mathrm{mg} / \mathrm{d} 1$ preoperatively. At three months after surgery, it was $216 \pm 40 \mathrm{mg} / \mathrm{dl}$, but at six months after surgery, it was $200 \pm 34 \mathrm{mg} / \mathrm{d} 1$. The mean HbAlc percentage was $8 \pm 0.8 \%$ preoperatively. At three months after surgery, it was $7.7 \pm 0.8 \%$, but at six months after surgery, it was $7.6 \pm 0.8 \%$. The mean triglyceride level 48 preoperatively. At three months after surgery, it was $162 \pm 41$, but at six months after surgery, it was $159 \pm 49$. The mean cholesterol was 207 \pm 42 preoperatively. At three months after surgery, it was 197 \pm 52 , but at six months after surgery, it was $189 \pm 41$. The HOMA-IR was $3 \pm 0.7$ preoperatively. At three months after surgery, it was $2.8 \pm 0.7$, but at six months after surgery, it was $2.8 \pm 0.7$. All the laboratory investigations change over time among the studied patients were not statistically significant.

Conclusion: So, we can conclude that large volume abdominal liposuction should not, by itself, be considered a clinical therapy for type 2 diabetes mellitus. Aspiration of large amounts of subcutaneous abdominal fat in diabetic patients, despite having cosmetic benefits, It does not significantly improve insulin sensitivity through altering serum levels of obesity markers. Therefore, the procedure is safe and may could successfully help diabetic subjects to reduce their potential metabolic risks. Therefore, abdominal Liposuction is effective scarless operation for subcutaneous adipose fatty tissue reduction.

Key Words: Liposuction - Newly diagnosed type 2 diabetes.

\section{Introduction}

DIABETES Mellitus (DM) is a metabolic disorder characterized by the presence of chronic hyperglycemia accompanied by greater or lesser impairment in the metabolism of carbohydrates, lipids and proteins. DM is probably one of the oldest diseases known to man. It was first reported in Egyptian manuscript about 3000 years ago. In 1936, the distinction between type 1 and type $2 \mathrm{DM}$ was clearly made. Type $2 \mathrm{DM}$ was first described as a component of metabolic syndrome in 1988. The origin and aetiology of DM can vary greatly but always include defects in either insulin secretion 
or response or in both at some point in the course of disease [1].

Mostly patients with diabetes mellitus have either type 1 diabetes (which is immune-mediated or idiopathic) Type $2 \mathrm{DM}$ (formerly known as noninsulin dependent DM) is the most common form of DM characterized by hyperglycaemia, insulin resistance, and relative insulin deficiency. Type 2 DM results from interaction between genetic, environmental and behavioral risk factors. Diabetes also can be related to the gestational hormonal environment, genetic defects, other infections, and certain drugs [1].

It is observed that complications of diabetes are increasing over the years and identifying these associations can be a strategy to outline measures to minimize the onset of early complications. Sociodemographic and clinical characteristics, along with this type of association can guide the management of care and educational programs for health professionals to monitor glucose levels of health services patients with diabetes [2].

Dyslipidaemia is a silent pandemic affecting millions of people around the world. There is more than one factor predisposing this serious problem, where not only diet, exercise, and medications could solve it. There is controversy of the possible benefit of liposuction or abdominoplasty in the metabolism of glucose or cholesterol. There are no reports about the effect of abdominoplasty in the metabolism of patients with dyslipidaemia. Observing any possible change in the lipid profile, weight, cardiovascular risk markers (HOMA), glucose, or insulin of patients with dyslipidaemia after an abdominoplasty or liposuction [6] .

Recently the ideas presenting relationship of regional adiposity with insulin sensitivity/resistance were not consistent and studies differed in the assessment of the importance of white adipose tissue (WAT) and brown adipose tissue (BAT). Some studies have suggested that the majority of metabolic activity in the adipose tissue belongs to WAT which is the most critical determinant of insulin sensitivity, whereas others have indicated the dominant role of BAT. The lack of consistent findings is probably attributed to the use of different methodologies (different type of liposuction procedure), small number of subjects, not homogenous study groups, differences in patient's lifestyle (exercise, diet), difficulties in maintaining stable body mass, and low sensitivity of an examination. At the moment, most authors agree that there is a positive correlation between accumulation of VAT and development of insulin resistance, while SAT determines leptin secretion which indirectly reflects the level of insulin sensitivity in the body [9] .

Liposuction has become the most common surgical procedure in plastic surgery over the past two decades. The popularity of liposuction stems from its utility and efficacy. Prior to the advent of liposuction techniques, the only method of removing fatty deposits was open lipectomy, which is associated with potentially high blood loss and significant scars. Liposuction, however, has provided a safe and effective method of removing fatty deposits without scarring [6].

The field of modem liposuction was initiated in 1974 by Arpad and Giuliano Fischer in Italy. It was only in 1987, however, that Jeffrey Klein innovated the field by developing the tumescent technique, which eliminated the high risk of excessive bleeding that is usually observed during liposuction surgeries, making it a much safer procedure. The development of the tumescent technique allowed the removal of greater amounts of fat in a much safer environment. This innovation, together with the knowledge that adipose tissue is a very metabolically active organ, led scientists to believe that liposuction could be a viable method for improving metabolic profile through the immediate loss of body fat mass, thus functioning as a possible co adjuvant in the treatment of obesity and comorbidities [3].

\section{Aim of the work:}

The aim of this study is to evaluate the effectiveness of abdominal liposuction in improving quality of life in newly diagnosed ncomplicated type 2 diabetic patients.

\section{Patients and Methods}

\section{A- Technical design:}

This study is an interventional study (pre post).

\section{Setting:}

This study will take place in Plastic Surgery Department, Port Said general Hospital.

\section{Sample size:}

As total number of cases satisfying inclusion criteria not exceed 6 cases per month during the study period ( 3 months) the total sample $3 \times 6=18$ cases all will be included as comprehensive sample. 


\section{Inclusion criteria:}

- Age group 30-50 yrs.

- Newly diagnosed uncomplicated type 2 DM.

- BMI 28.

- Dyslipidemic patients.

- Elevated $\mathrm{HbA} 1 \mathrm{c} \geq 6.5 \%$.

- HOMA-IR value $<2$.

- Age below 30 yrs and above 50 yrs.

- Type 1 DM.

- Renal impairment.

- Chronic liver disease.

- Chronic lung disease.

- Ischemic heart disease.

- Pregnancy and lactation.

- Neurological deficit.

- Ongoing anticoagulant medication.

- Bleeding diathesis.

Study design:

- Physical examination of the patient.

- Preparation of the patient for surgery by:

- Preoperative investigation: CBC, liver function test, kidney function test, PT, PTT, INR, HbA1c, lipid profile, HOMA-IR.

- Pelvic-abdominal ultrasonography.

- Preoperative consultation: Anaesthesia consultation, any other consultation if needed.

- Stop smoking before procedure by 2 weeks.

- Preoperative photography and informed consent from the patient.

\section{B- Operational design:}

Classic liposuction also known as suctionassisted liposuction (SAL) uses aspiration techniques to break down and draw the fat cells out of the body. In this method small cannula is inserted through a small incision and attached to a vacuum device. There are many different types of liposuction according to the volume of infiltration or wetting solution injected before the surgery: dry, wet, superwet and tumescent technique. Moreover, the surgery could be modified by the new technologies.

\section{Methods:}

All subjects were submitted to the following:

1- Careful history taking including:

2- Basic medical histories.
3- Baseline characteristics, including age, sex, hypertension, family history and previous medications.

4- Thorough clinical examination was performed with special emphasis on signs of diabetic complications. Weight, height and Body Mass Index (BMI) were calculated by dividing weight in $\mathrm{kg}$ by height in $\mathrm{m}^{2}$ according to Global Database on Body Mass Index, World Health Organization (WHO, 2006). The examination included also vital signs and cardiac, respiratory, abdominal and neurological assessment.

5- Preparation of the patient for surgery by:

- Preoperative investigations (CBC, liver function test, kidney function test, PT, PTT, INR, HbA1c, lipid profile and HOMA-IR).

- Pelvic-abdominal ultrasonography.

- Preoperative consultation (anesthesia consultation and any other consultation if needed).

- Stop smoking before procedure by 2 weeks.

6- Preoperative photography and informed consent from the patient.

\section{7- Liposuction.}

\section{Homeostasis model assessment:}

All participants were subjected to the assessment of fasting glucose and insulin levels. Blood samples were taken twice from liposuction candidates; 48-hours pre-operatively and 10 to 12 weeks postoperatively. The 10-to-12-week delay was intended to eliminate the confounding effects of postsurgical inflammation on our study end points. Serum was separated by centrifugation within 30 minutes after collection and stored at $-70{ }^{\circ} \mathrm{C}$ until final analyses were performed. Plasma glucose concentrations were determined enzymatically. Enzyme-linked immunosorbent assay kits were used to measure insulin level. Insulin sensitivity was measured by the Homeostasis Model Assessment $($ HOMA $=$ Fasting plasma glucose $\mathrm{x}$ fasting serum insulin divided by 25 ).

\section{Abdominal liposuctton:}

Classic liposuction also known as suctionassisted liposuction (SAL) uses aspiration techniques to break down and draw the fat cells out of the body. In this method, small cannula is inserted through a small incision and attached to a vacuum device. There are many different types of liposuction according to the volume of infiltration or wetting solution injected before the surgery: Dry, wet, superwet and tumescent technique. Moreover, the surgery could be modified by the new technologies such as power assisted liposuction (PAL), 
ultrasound assisted liposuction (UAL) and laser assisted liposuction (LAL). According to the volume of solution, aspirated liposuction could be divided into two categories: Large volume liposuction ( $>5$ litres aspirated) and small volume liposuction ( $<5$ litres aspirated).

The most popular liposuction types are tumescent and superwet techniques with minimal risk of bleeding complications and small volume fluid infusions during surgery. Tumescent liposuction is performed under local anaesthesia after subcutaneous infusion of fluid (most commonly containing saline, lidocaine, and epinephrine, with or without sodium bicarbonate) in a ratio of $2-3 \mathrm{~mL}$ of infiltrate to $1 \mathrm{ml}$ of aspirate; the endpoint of infiltration is tissue turgor. For the best results, liposuction candidates should be healthy and physically fit and not more than 20 pounds overweight, their skin should be firm and elastic [9] .

No serious complications occurred in any subject and all were able to return to their usual lifestyle within 10 days after liposuction. Hypoglycemic medications were regulated by the subject's physician. Re-evaluation of BMI and waist circumference was undertaken 10-12 weeks post-operatively.

\section{Results}

This interventional study was conducted on 11 subjects. It included 6 males and 5 females.

Table (1): Gender distribution among the studied patients $(n=11)$.

\begin{tabular}{lcc}
\hline Gender & Frequency & Percent \\
\hline Male & 6 & $54.5 \%$ \\
Female & 5 & $45.5 \%$ \\
\hline Total & 11 & $100 \%$ \\
\hline
\end{tabular}

The mean FPG was $163 \pm 22 \mathrm{mg} / \mathrm{d} 1$ preoperatively. At three months after surgery, it was $162 \pm$ $29 \mathrm{mg} / \mathrm{d} 1$, but at six months after surgery, it was $147 \pm 28 \mathrm{mg} / \mathrm{d} 1$. The mean FPG change was nonsignificantly different over time among the studied patients $(p>0.05)$ (Table 2$)$.

Table (2): Comparison of FBG change over time among the studied patients $(n=11)$.

\begin{tabular}{lllll}
\hline FBG & Pre-op & $3 \mathrm{~m}$. & $6 \mathrm{~m}$. & $p$-value \\
\hline Mean \pm SD & $163 \pm 22$ & $162 \pm 29$ & $147 \pm 28$ & $0.279 *$ \\
Range & $(118-192)$ & $(104-201)$ & $(112-189)$ & \\
Median & 164 & 167 & 144 & \\
\hline
\end{tabular}

The mean PPBG was $218 \pm 40 \mathrm{mg} / \mathrm{d} 1$ preoperatively. At three months after surgery, it was $216 \pm$
$40 \mathrm{mg} / \mathrm{dl}$, but at six months after surgery, it was $200 \pm 34 \mathrm{mg} / \mathrm{d} 1$. The mean PPBG change was nonsignificantly different over time among the studied patients $(p>0.05)$ (Table 3$)$.

Table (3): Comparison of PPBG change over time among the studied patients $(n=11)$.

\begin{tabular}{lllll}
\hline PPBG & Pre_op & $3 \mathrm{~m}$. & $6 \mathrm{~m}$. & $p$-value \\
\hline Mean \pm SD & $218 \pm 40$ & $216 \pm 40$ & $200 \pm 34$ & $0.479 *$ \\
Range & $(145-279)$ & $(143-296)$ & $(160-264)$ & \\
Median & 212 & 213 & 207 & \\
\hline
\end{tabular}

Table (4): Post HOC Tukey comparison of PPBG change over time among the studied patients $(n=11)$.

\begin{tabular}{ccccccc}
\hline & & & & \multicolumn{2}{c}{$\begin{array}{c}\text { 95\% Confidence } \\
\text { interval }\end{array}$} \\
\cline { 6 - 7 } cases & $\begin{array}{c}(\mathrm{J}) \\
\text { cases }\end{array}$ & $\begin{array}{c}\text { Mean } \\
\text { difference } \\
\text { (I-J) }\end{array}$ & $\begin{array}{c}p^{-} \\
\text {value }\end{array}$ & & $\begin{array}{c}\text { Lower } \\
\text { bound }\end{array}$ & $\begin{array}{c}\text { Upper } \\
\text { bound }\end{array}$ \\
\hline Pre-op & $3 \mathrm{~m}$. & 1.45455 & $0.996^{*}$ & -38.4993 & 41.4084 \\
& $6 \mathrm{~m}$. & 17.90909 & $0.518^{*}$ & -22.0448 & 57.863 \\
$3 \mathrm{~m}$. & Pre-op & -1.45455 & $0.996^{*}$ & -41.4084 & 38.4993 \\
& $6 \mathrm{~m}$. & 16.45455 & $0.573^{*}$ & -23.4993 & 56.4084 \\
$6 \mathrm{~m}$. & Pre-op & -17.90909 & $0.518^{*}$ & -57.863 & 22.0448 \\
& $3 \mathrm{~m}$. & -16.45455 & $0.573^{*}$ & -56.4084 & 23.4993 \\
\hline
\end{tabular}

The mean HbAlc percentage was $8 \pm 0.8 \%$ preoperatively. At three months after surgery, it was $7.7 \pm 0.8 \%$, but at six months after surgery, it was $7.6 \pm 0.8 \%$. The mean PPBG change was nonsignificantly different over time among the studied patients $(p>0.05)$ (Table 5).

Table (5): Comparison of $\mathrm{Hb}$ Alc change over time among the studied patients $(n=11)$.

\begin{tabular}{lllll}
\hline HbAlc & Pre-op & $3 \mathrm{~m}$. & $6 \mathrm{~m}$. & $p$-value \\
\hline Mean \pm SD & $8 \pm 0.8$ & $7.7 \pm 0.8$ & $7.6 \pm 0.8$ & $0.382^{*}$ \\
Range & $(6.9-9.4)$ & $(6.5-8.9)$ & $(6.8-9.1)$ & \\
Median & 7.8 & 7.4 & 7.5 & \\
\hline
\end{tabular}

The mean triglyceride level was $180 \pm 48$ preoperatively. At three months aser surgery, it was $162 \pm 41$, but at six months after surgery, it was $159 \pm 49$. The mean triglyceride change was nonsignificantly different over time among the studied patients $(p>0.05)$ (Table 6).

Table (6): Comparison of Triglycerides change over time among the studied patients $(n=11)$.

\begin{tabular}{llllr}
\hline Triglycerides & Pre-op & $3 \mathrm{~m}$. & $6 \mathrm{~m}$. & $p$-value \\
\hline Mean \pm SD & $180 \pm 48$ & $162 \pm 41$ & $159 \pm 49$ & $0.524^{*}$ \\
Range & $(136-270)$ & $(112-234)$ & $(111-286)$ & \\
Median & 164 & 158 & 143 & \\
\hline
\end{tabular}


Table (7): Post DOC Tukey comparison of Triglycerides change over time among the studied patients $(n=11)$.

\begin{tabular}{|c|c|c|c|c|c|}
\hline \multirow{2}{*}{$\begin{array}{l}\text { (I) } \\
\text { cases }\end{array}$} & \multirow{2}{*}{$\begin{array}{l}(\mathrm{J}) \\
\text { cases }\end{array}$} & \multirow{2}{*}{$\begin{array}{c}\text { Mean } \\
\text { difference } \\
(\mathrm{I}-\mathrm{J})\end{array}$} & \multirow{2}{*}{$\begin{array}{c}p- \\
\text { value }\end{array}$} & \multicolumn{2}{|c|}{$\begin{array}{l}95 \% \text { Confidence } \\
\text { interval }\end{array}$} \\
\hline & & & & $\begin{array}{l}\text { Lower } \\
\text { bound }\end{array}$ & $\begin{array}{l}\text { Upper } \\
\text { bound }\end{array}$ \\
\hline Pre-op & $\begin{array}{l}3 \mathrm{~m} . \\
6 \mathrm{~m} .\end{array}$ & $\begin{array}{l}17.81818 \\
20.90909\end{array}$ & $\begin{array}{l}0.64 * \\
0.543 *\end{array}$ & $\begin{array}{l}-30.636 \\
-27.5451\end{array}$ & $\begin{array}{l}66.2724 \\
69.3633\end{array}$ \\
\hline $3 \mathrm{~m}$. & $\begin{array}{l}\text { Pre-op } \\
6 \mathrm{~m} .\end{array}$ & $\begin{array}{l}-17.81818 \\
3.09091\end{array}$ & $\begin{array}{l}0.64^{*} \\
0.986^{*}\end{array}$ & $\begin{array}{l}-66.2724 \\
-45.3633\end{array}$ & $\begin{array}{l}30.636 \\
51.5451\end{array}$ \\
\hline $6 \mathrm{~m}$. & $\begin{array}{l}\text { Pre-op } \\
3 \mathrm{~m} .\end{array}$ & $\begin{array}{l}-20.90909 \\
-3.09091\end{array}$ & $\begin{array}{l}0.543 * \\
0.986 *\end{array}$ & $\begin{array}{l}-69.3633 \\
-51.5451\end{array}$ & $\begin{array}{l}27.5451 \\
45.3633\end{array}$ \\
\hline
\end{tabular}

The mean cholesterol was $207 \pm 42$ preoperatively. At three months after surgery, it was $197 \pm 52$, but at six months after surgery, it was $189 \pm 41$. The mean cholesterol change was non-significantly different over time among the studied patients $(p>0.05)$ (Table 7).

The HOMA-IR was $3 \pm 0.7$ preoperatively. At three months after surgery, it was $2.8 \pm 0.7$, but at six months after surgery, it was $2.8 \pm 0.7$. The mean HOMA-IR change was non-significantly different over time among the studied patients $(p>0.05)$ (Table 8).

Table (8): Comparison of HOMA IR change over time among the studied patients $(n=11)$.

\begin{tabular}{lllll}
\hline HOMA IR & Pre_op & \multicolumn{1}{c}{$3 \mathrm{~m}}$. & $6 \mathrm{~m}$. & $p$-value \\
\hline Mean \pm SD & $3 \pm 0.7$ & $2.8 \pm 0.7$ & $2.8 \pm 0.7$ & $0.804^{*}$ \\
Range & $(2.1-4.6)$ & $(1.9-3.9)$ & $(2.1-4.2)$ & \\
Median & 2.8 & 2.7 & 2.7 & \\
\hline
\end{tabular}

Studied patient number (1)

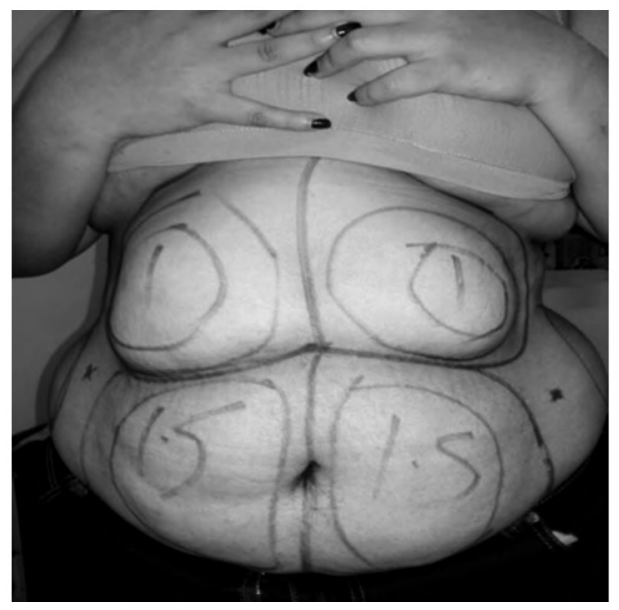

Before
Table (9): Post HOC Tukey comparison of HOMA IR change over time among the studied patients $(n=11)$.

\begin{tabular}{lllclll}
\hline & & & & \multicolumn{2}{c}{$95 \%$ Confidence } \\
(I) & \multicolumn{1}{c}{$(\mathrm{J})$} & $\begin{array}{c}\text { Mean } \\
\text { difference } \\
\text { cases }\end{array}$ & cases & $\begin{array}{c}p- \\
\text { value }\end{array}$ & & \multicolumn{2}{c}{$\begin{array}{c}\text { Lower } \\
\text { bound }\end{array}$} & $\begin{array}{c}\text { Upper } \\
\text { bound }\end{array}$ \\
\hline Pre-op & $3 \mathrm{~m}$. & 0.19091 & $0.793 *$ & -0.5322 & 0.914 \\
& $6 \mathrm{~m}$. & 0.12727 & $0.902 *$ & -0.5958 & 0.8503 \\
$3 \mathrm{~m}$. & Pre-op & -0.19091 & $0.793 *$ & -0.914 & 0.5322 \\
& $6 \mathrm{~m}$. & -0.06364 & $0.974 *$ & -0.7867 & 0.6594 \\
$6 \mathrm{~m}$. & Pre-op & -0.12727 & $0.902 *$ & -0.8503 & 0.5958 \\
& $3 \mathrm{~m}$. & 0.06364 & $0.974 *$ & -0.6594 & 0.7867 \\
\hline
\end{tabular}

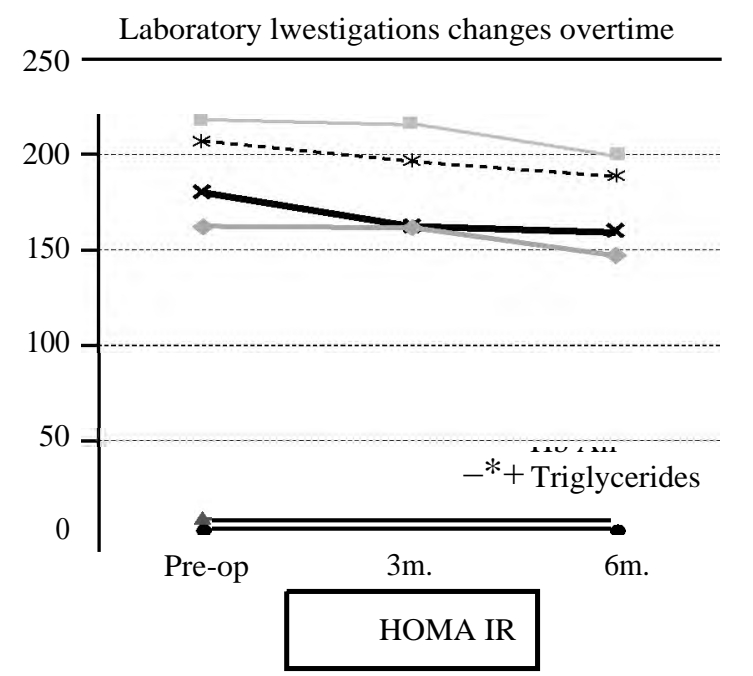

Fig. (1): Comparison of laboratory investigations change over time among the studied patients $(n=11)$.

All the laboratory investigations change over time among the studied patients was not statistically significant ( $p$-value $>0.05)$, as shown in Fig. (1).

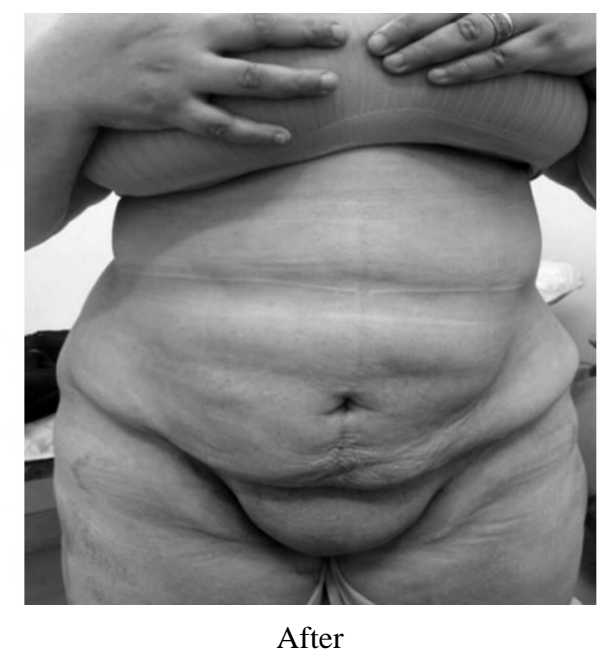

Fig. (2): 40 years old female patient with chronic hypertension, newly diagnosed type 2 diabetes since 5 months, dislipidemic before and after 3 months of abdominal liposuction. 
Studied patient number (2).

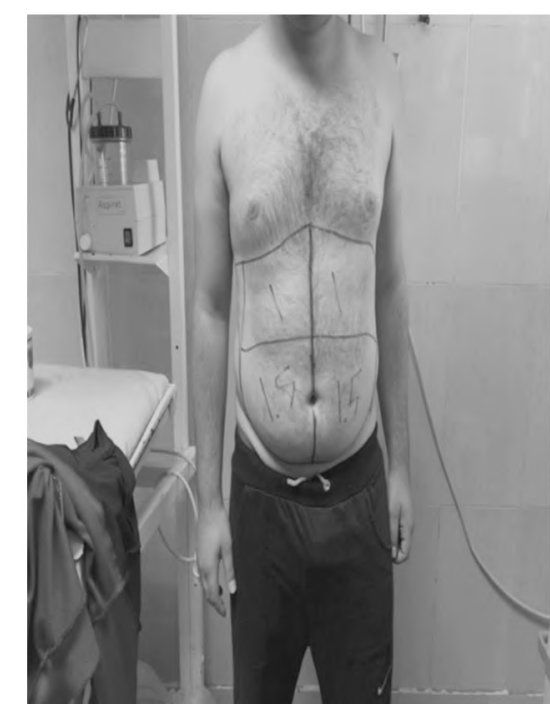

Before

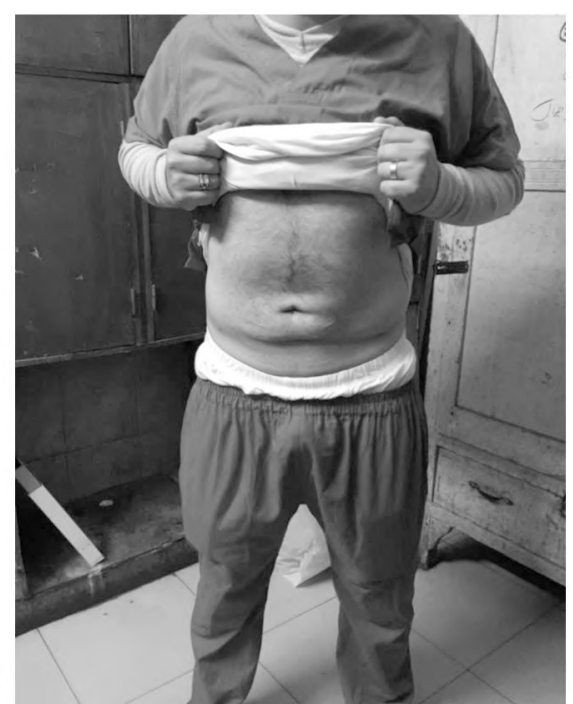

After

Fig. (3): 37 years old male patient with history of type 2 diabetes 4 years ago with no other disease before and after 3 months of abdominal liposuction.

Studied patient number (3).

Before
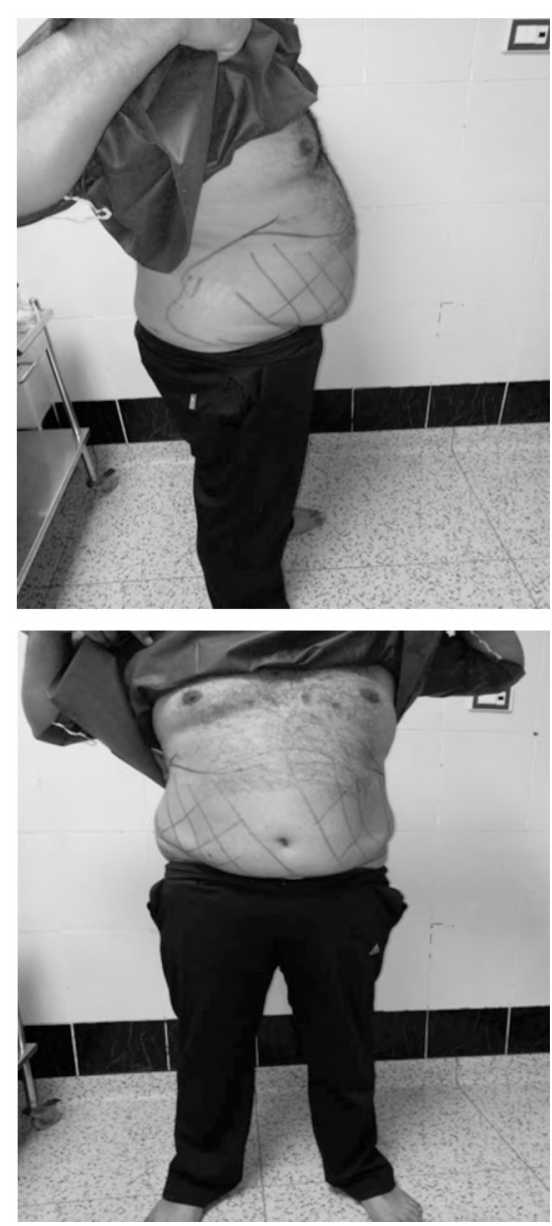

After
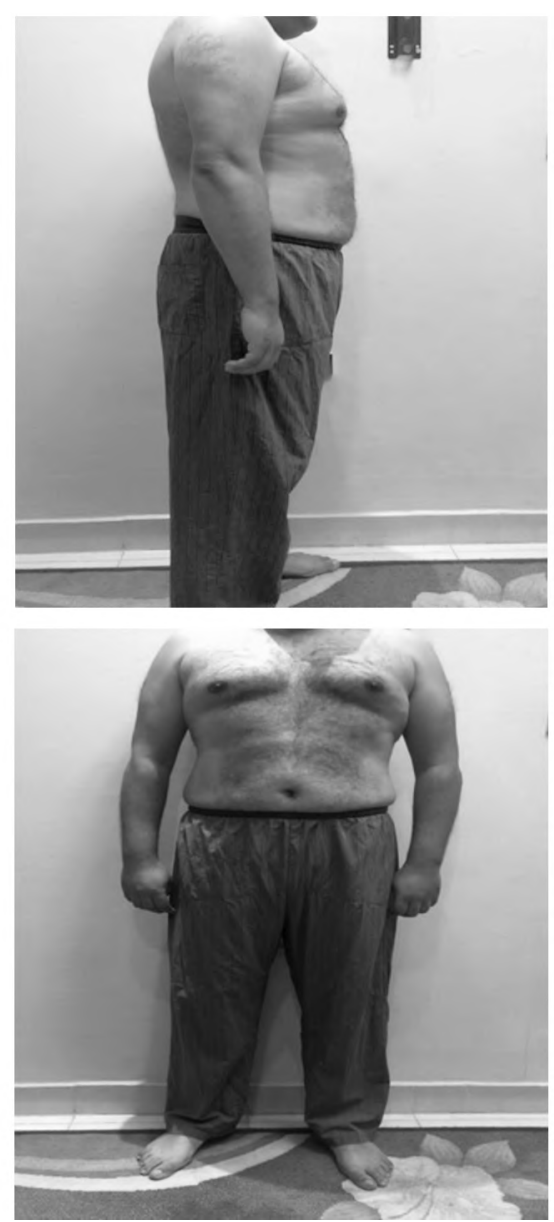

Fig. (4): 39 years old male patient with history of type 2 diabetes 2 years ago with dyslipidemia before and after 5 months of abdominal liposuction. 
Studied patient number (4).
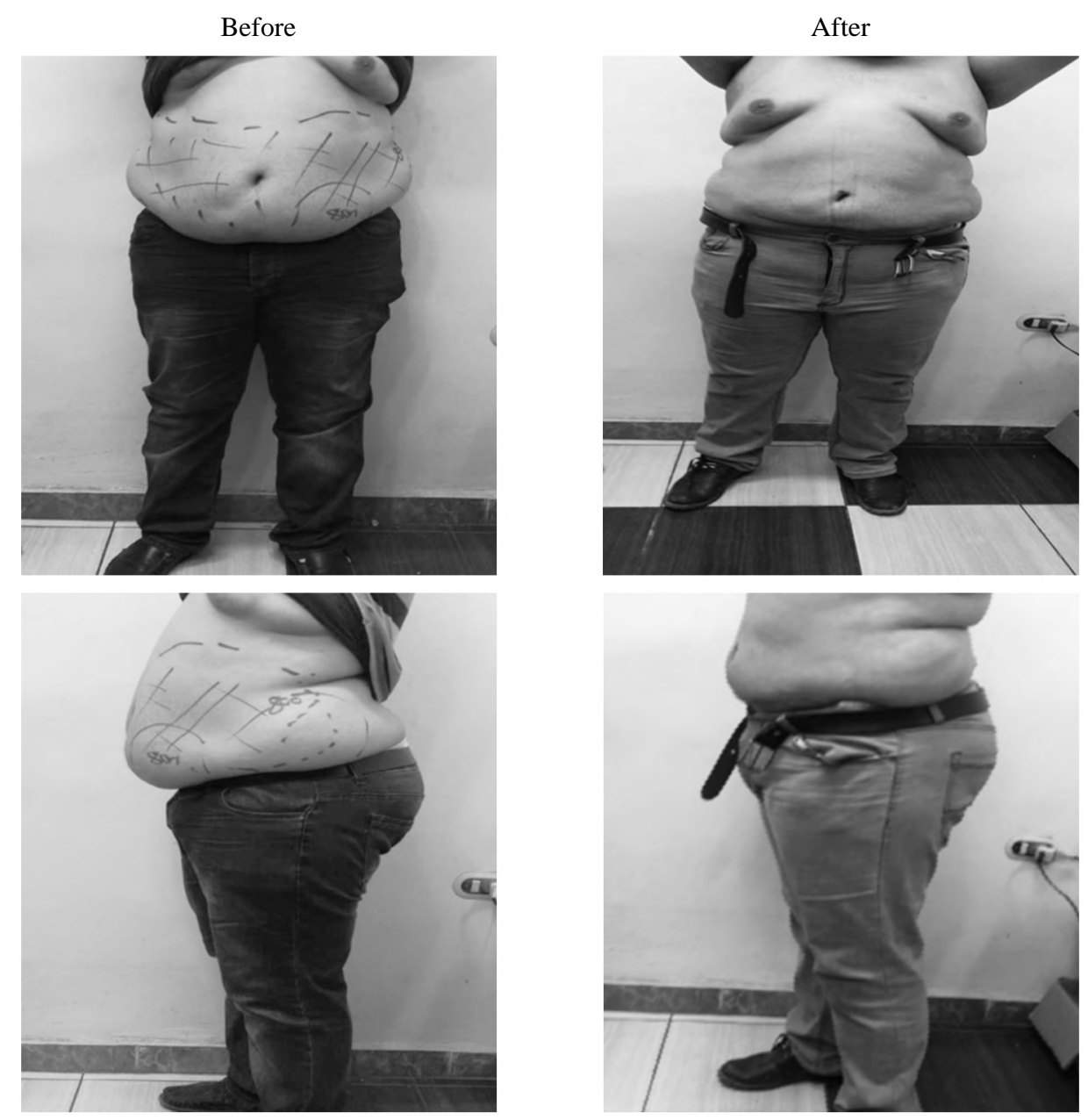

Fig. (5): 44 years old male patient with history of type 2 diabetes from 1 year with hypertension and dyslipidemia before and after 4 months of abdominal liposuction.

\section{Discussion}

Diabetes mellitus is a group of metabolic disease characterized by hyperglycemia resulting from defect in insulin secretion, insulin action or both. The chronic hyperglycemia of diabetes associated with long-term damage, dysfunction and failure of different organs especially the eyes, kidneys, nerves and blood vessels. It affects 366 million people worldwide (6.4\% of the adult population) and is expected to rise to 552 million by 2030 [12]

Therefore, this interventional study (pre-post) was conducted in the Department of Plastic Surgery, Port Said General Hospital and Ain Shams University to study the effectiveness of abdominal liposuction in improving quality of life in newly diagnosed uncomplicated type 2 diabetic patients in 11 subjects. It included 6 males and 5 females. The patients were subjected to physical examination of the patient, preparation for surgery by preoperative investigations including (CBC, liver function test, kidney function test, PT, PTT, INR, HbA1c, lipid profile and HOMA-IR), pelvic-abdominal ultrasonography and preoperative consultation] and preoperative photography.

After abdominal liposuction, no serious complications occurred in any subject and all were able to return to their usual lifestyle within 10 days afler liposuction. Hypoglycemic medications were regulated by the subject's physician. Re-evaluation of BMI and waist circumference was undertaken 10-12 weeks post-operatively.

In our study, the mean FPG was $163 \pm 22 \mathrm{mg} / \mathrm{d} 1$ preoperatively. At three months after surgery, it was $162 \pm 29 \mathrm{mg} / \mathrm{d} 1$, but at six months after surgery, it was $147 \pm 28 \mathrm{mg} / \mathrm{d} 1$. The mean PPBG was $218 \pm$ $40 \mathrm{mg} / \mathrm{d} 1$ preoperatively. At three months after surgery, it was $216 \pm 40 \mathrm{mg} / \mathrm{d} 1$, but at six months after surgery, it was $200 \pm 34 \mathrm{mg} / \mathrm{d} 1$. The mean HbAlc percentage was $8 \pm 0.8 \%$ preoperatively. At three months after surgery, it was $7.7 \pm 0.8 \%$, but 
at six months after surgery, it was $7.6 \pm 0.8 \%$. The mean triglyceride level was $180 \pm 48$ preoperatively. At three months after surgery, it was $162 \pm 41$, but at six months after surgery, it was $159 \pm 49$. The mean cholesterol was $207 \pm 42$ preoperatively. At three months after surgery, it was $197 \pm 52$, but at six months after surgery, it was $189 \pm 41$. The HOMA-IR was $3 \pm 0.7$ preoperatively. At three months afler surgery, it was $2.8 \pm 0.7$, but at six months after surgery, it was $2.8 \pm 0.7$. All the laboratory investigations change over time among the studied patients were not statistically significant ( $p$-value $>0.05$ ). It is demonstrated that after 12 weeks of stable body weight post-liposuction, obese women turned to be less insulin resistant. They also emphasized a significant correlation between the amount of fat aspirate and changes in HOMA [4]

Benefits of weight loss added that even small amounts of weight loss induced by a negative energy balance affect many variables pertaining to body-fat composition and lipid metabolism that probably contribute to the metabolic abnormalities associated with obesity Liew implicated that negative energy balance influences adipocyte and monocyte activation and thereby gene expression that encodes for adiponectin and other related adipocytokines [7]

Perez implicated that weight reduction through large volume abdominal liposuction has undoubted influences on insulin resistance and other metabolic sequelae of obesity. This signifies that surgical removal of subcutaneous adipose tissue, though it does not entail alteration of energy balance or visceral fat integrity, yet by virtue of significant reduction of fat cell mass, it can achieve comparable metabolic impacts to that of other conventional weight-reducing therapeutic modalities. Adipose tissue is now recognized as an important endocrine organ that produces several bioactive proteins, including leptin, adiponectin, interleukin- 6 and tumor necrosis factor. These cytokines are collectively responsible for insulin resistance by impairing insulin signaling, stimulating lipolysis and fatty acid release, increasing hepatic synthesis of Creactive protein, and increasing systemic inflammation. Fat loss achieved by conventional obesity treatments decreases the plasma concentrations of C- reactive protein, interleukin- 6 and tumor necrosis factor and increases the concentration of adiponectin [11].

Maher and Kamel [8] assessed the effects of large volume abdominal liposuction on serum adiponectin level and its impact on insulin resistance in obese women. Forty female subjects were submitted for the study. Eleven obese women who had normal glucose tolerance (BMI, $37.1 \pm 3.4$ ), nine obese women who had type 2 diabetes (BMI, $39.9 \pm 5.6)$ and twenty healthy premenopausal agematched normal weight (BMI <25) women were taken as control.

Concerning baseline data, there was statistically significant difference in BMI, waist circumference and HOMA between the control group and obese groups. There was also a statistically significant difference in HOMA between obese nondiabetics and obese diabetics. However, there was no statistically significant difference in BMI and waist circumference between obese non-diabetics compared to obese diabetics. They revealed that liposuction has resulted in significant decrease in insulin resistance; as indicated by HOMA. They proved a significant correlation between the amount of fat aspirate and changes in body weight, waist circumference and HOMA in diabetics [8] .

Maher and Kamel [8] demonstrated that liposuction is safe and is associated with amelioration of metabolic consequences of obesity which may help obese subjects to reduce their insulin resistance.

Narsete investigated the effects of large-volume liposuction on the parameters that determine type 2 diabetes. The study enrolled 31 patients with a body mass index (BMI) exceeding $30 \mathrm{~kg} / \mathrm{m}^{2}$ over a l-year period. All the liposuction procedures were performed with the patient under local anesthesia using ketamine/valium sedation. Pre- and postoperative blood pressure, fasting glucose, glycated hemoglobin $(\mathrm{HbAlC})$, weight, and BMI were evaluated for 16 of the 30 patients who returned for a follow-up visit 3 to 12 months postoperatively. The average aspirate was $8,455 \mathrm{ml}$ without dermolipectomy and $5,795 \mathrm{ml}$ with dermolipectomy. They revealed a trend of improvement in blood sugar levels associated with weight loss that helps the patients. The average blood sugar level dropped $18 \%$ in our return patients, and the average weight loss was $9.2 \%$. The average drop in BMI was $6.2 \%$, and $\mathrm{HbAlC}$ showed a decrease of $2.3 \%$. The patients with the best weight loss had the best reduction in blood sugar level and blood pressure. No transfers to the hospital and thromboembolism occurred for any of the 31 patients. One dehiscence, two wound infections, and three seromas were reported. They hypothesized that large-volume liposuction in their series may have motivated some to diet, which could be explored in a larger series with control groups. Liposuction alone did not improve obesity but helped to motivate some 
of the patients to lose weight. These patients had the best results. From the results of the present study, we can state that complications are minor and infrequent, and patients are able to return to normal daily activities within 3 to 4 days [10]

\section{Conclusion:}

After the procedure. Sports and heavy physical activities can be gradually resumed, and patient satisfaction is excellent. So, we can conclude that large-volume abdominal liposuction should not, by itself, be considered a clinical therapy for type 2 diabetes mellitus. Aspiration of large amounts of subcutaneous abdominal fat in diabetic patients, despite having cosmetic benefits, It does not significantly improve insulin sensitivity through altering serum levels of obesity markers. Therefore, the procedure is safe and may could successfully help diabetic subjects to reduce their potential metabolic risks. Therefore, abdominal Liposuction is effective scarless operation for subcutaneous adipose fatty tissue reduction.

\section{References}

1- BAYNES H.W.:Classifcation, Pathophysiology, Diagnosis and Management of Diabetes Mellitus, 2015.

2- DANIEL NOGUEIRA CORTEZ, ILKA AFONSO REIS, DÉBORA APARECIDA SILVA SOUZA and MAÍSA MARA LOPES MACEDO: Complications and the time of diagnosis of diabetes mellitus in primary care i., 28 (3): 250-5, 2015.

3- FABIANA BRAGA BENATTI, FÁBIO SANTOS LIRA, LILA MISSAE OYAMA, CLÁUDIA MARIA DA PENHA OLLER DO NASCIMENTO and ANTONIO HERBERT LANCHA: Strategies for reducing body fat mass: effects of liposuction and exercise on cardiovascular risk factors and adiposity, 141: 154, 2011.

4- GIUGLIANO G., NICOLETTI G., GRELLA E., GIUGEANO F., ESPOSITO K., SCUDERI N. and
D'ANDREA F.: Effect of liposuction on insulin resistance and vascular infl ammatory markers in obese women. $\mathrm{Br}$. J. Plast. Surg., 57 (3): 19CE-194, 2004.

5- GUILLERMO RAMOS-GALLARDO, ANA PÉREZ VERDIN, MIGUEL FUENTES A., SERGIO GODÍNEZ GUTIÉRREZ, ANA ROSA AMBRIZ, PLASCENCIA, IGNACIO GONZÁLEZ-GARCÍA, SONIA MERIEIA GÓMEZ-FONSECA, ROSALIO ADRIGAL, LUIS IVFIN GONZÁLEZ-REYNOSO, SANDRA FIGUEROA and XAVIERTOSCANO IGARTUA: Effect of Abdominoplasty in the Lipid Profile of Patients with Dyslipidemia, 2013.

6- HABBEMA L.: Breast reduction using liposuction with tumescent local mesthesia and powered cannulas. Dermatol. Surg., 35 (1): 41-52, 2009.

7- LIEW G., KLEIN R. and WONG T.Y.: The role of genetics in susceptibility to diabetic retinopathy. Int. Ophthalmol. Clin., 49 (2): 35-52, 2009

8- MAHER A. and KAMEL I.: Effect of large-volume abdominal liposuction on serum adiponectin level and its metabolic consequences in obese women. Egypt, J. Plast. Reconstr. Surg., 33 (2): 201-208, 2009.

9- MAGDALENA GIBAS-DORNAL, PIOTR TURKOWSKI, MALGORZATA BERNATEK, KINGA MIKRUT, JUSTYNA KUPSZ, JACEK PIATEK: Liposuction-induced metabolic alterations - the effect on insulin sensitivity, adiponectin, leptin and resistin, p 254.

10-NARSETE T., NARSETE M., BUCKSPAN R. and ERSEK R.: Large-volume liposuction and prevention of type 2 diabetes: A preliminary report. Aesthetic Plast. Surg., 36 (2): 438-42, 2012.

11-PEREZ R.A.: Liposuction and diabetes type 2 development risk reduction in the obese patient. Med. Hypotheses, 68 (2): 393-396, 2007.

12- ZUBIN PUNTHAKEE M.D., M.Sc., FRCPC, RONALD GOLDENBERG M.D., FRCPC, FACE \& PAMELAKATZ M.D., FRCPC: Definition, Classification and Diagnosis oï Diabetes, Prediabetes and Metabolic Syndrome: Diabetes Canada Clinical Practice Guidelines Expert Committee Can. J. Diabetes, 42: SU- Si, 2018. 


\section{تقييم تأثير شفط دهون البطن فى التغيرات الأيضية

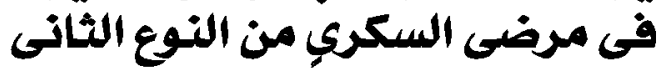 المكتشفين حلديثا بلدون مضاعفات النيكان}

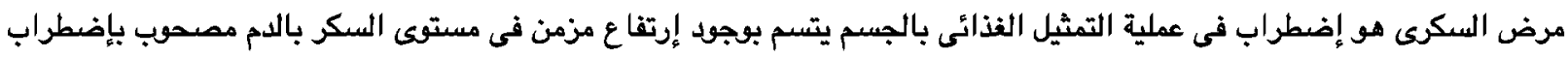

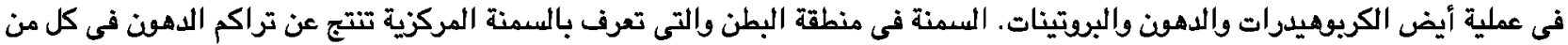

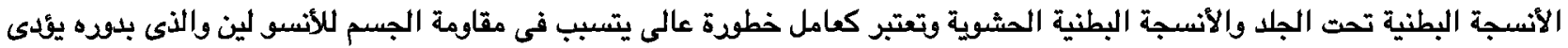

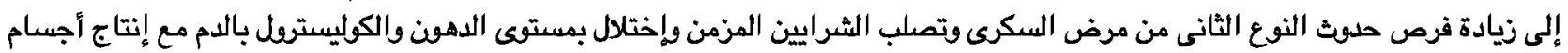

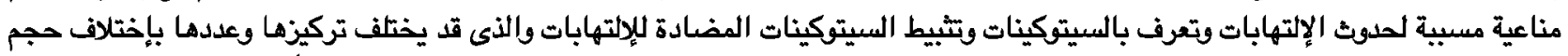

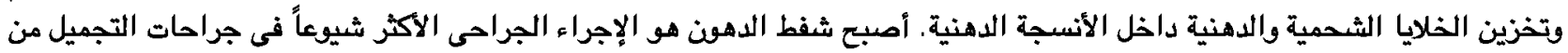

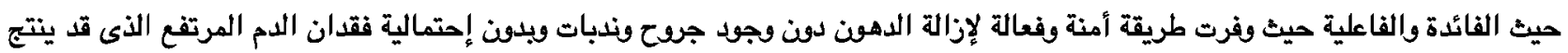

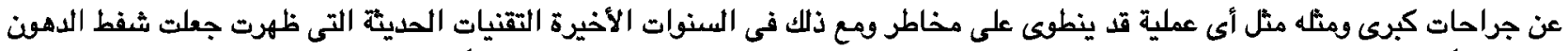

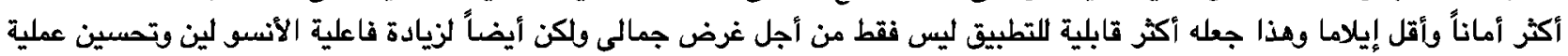

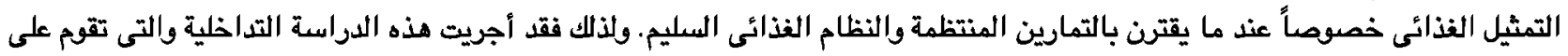

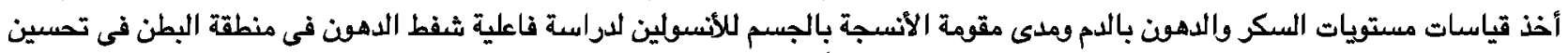

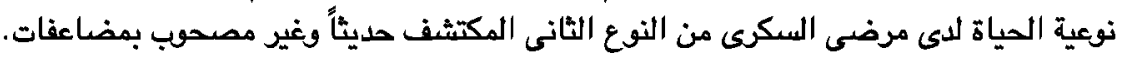

